\title{
Visible Light Assisted Gasochromic Sensing of Nicotine from Cigarette Smoke by Metal-Organic Nanotube
}

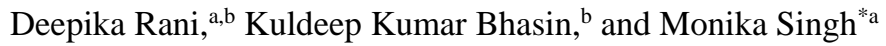 \\ anstitute of Nano Science and Technology, Sector-64, Phase-10, Mohali-160062, INDIA \\ ${ }^{\text {b} D e p a r t m e n t ~ o f ~ C h e m i s t r y, ~ P a n j a b ~ U n i v e r s i t y, ~ S e c t o r-14, ~ C h a n d i g a r h-160014, ~ I N D I A ~}$ \\ E-mail: monika@inst.ac.in; 8monik@gmail.com
}

Supporting information 


\section{Synthesis of $\left[\mathrm{Zn}_{3}(\mathrm{btc})_{2}(\mu 3-\mathrm{OH})(\mathrm{DMF})\right] . \mathrm{H}_{2} \mathrm{O}, 1$}

The reagents and solvents are commercially purchased from TCI, India and was used without further purification.

$\mathrm{Zn}\left(\mathrm{NO}_{3}\right)_{2} .6 \mathrm{H}_{2} \mathrm{O}(0.00594 \mathrm{~mol}, \mathrm{TCI}, 98 \%)$ and 1,3,5-benzenetricarboxylic acid (btc) $(0.00594 \mathrm{~mol}$, TCI, 98\%) were added in 1:1 ratio to a mixture of DMF and Ethanol (1:2) and taken in a $25 \mathrm{ml}$ capacity Teflon lined stainless steel acid digestion reactor and heated at $85^{\circ} \mathrm{C}$ for 24 hours. Pale yellow coloured rectangular block shaped crystals of 1 was obtained which was then washed with methanol and dried in air. IR $(\mathrm{KBr}): v=1623$ (s) and 1578(s) attributed to asymmetric stretching of carboxylate group, 1435 (s) and 1353 (s) are due to symmetric stretching carboxylate group. Anal. calcd for 1: C 35.12, H 2.09, N 1.95; found: C 35.34, H 2.14, N 2.01

\section{X-ray Structure Determination}

X-ray diffraction studies (of 1) crystal mounted on Hampton cryoloops. All geometric and intensity data for the crystals were collected using a Super-Nova (Mo) X-ray diffractometer equipped with a micro-focus sealed X-ray tube Mo-K $\alpha(\lambda=0.71073 \AA)$ X-ray source, and HyPix 3000 detector with increasing $\omega$ (width of 0.3 per frame) at a scan speed of either 5 or 10 s/frame. The CrysAlisPro software was used for data acquisition, and data extraction. Using Olex $2,{ }^{1}$ the structure was solved with the SIR $2004^{2}$ structure solution program using Direct Methods and refined with the ShelXL ${ }^{3}$ refinement package using Least Squares minimization. All non- hydrogen atoms were refined with anisotropic thermal parameters. Crystal and refinement data are summarized in Table S1.

\section{Other Physical Measurements}

Room-temperature powder X-ray diffraction data were collected on a Bruker D8 Eco Diffractometer using $\mathrm{Ni}$-filtered $\mathrm{Cu} \mathrm{K} \alpha$ radiation. Data were collected with a step size of $0.02^{\circ}$ over the range $2^{\circ}<2 \theta<80^{\circ}$. TG analysis was carried out using Perkin-Elmer STA 8000 system on well ground samples in flowing nitrogen atmosphere at a heating rate of $10{ }^{\circ} \mathrm{C} / \mathrm{min}$. Scanning electron microscopy (SEM) images were observed with a Jeol JSM IT 300 system, USA. Diffusion reflectance spectroscopy was carried out on UV/Vis spectrophotometer (Shimadzu UV-2600). Solid state photoluminescence was recorded on Fluorolog 3-221 (Horiba Scientific).

\section{Gas Chromatography studies}


The quantification of concentration of nicotine in different brand of cigarette was carried out using gas chromatography (Schimadzu GC-MS- 2014) coupled with a GCMS-QP 2010 plus mass detector (GC-MS) and a single-quadrupole mass spectrometer Quantum (Shimadzu) with $100 \%$ dimethyl polysiloxane. The analytical column was a Restek Rxi-1ms $(30 \mathrm{~m} \times 0.25 \mathrm{~mm}$ i. d. $\times 0.25 \mu \mathrm{m}$ d.f). GC-MS operating conditions: Initial column oven temperature was $50{ }^{\circ} \mathrm{C}$, increased to $150{ }^{\circ} \mathrm{C}$ at $10{ }^{\circ} \mathrm{C} / \mathrm{min}$ and held for 2 minutes, then ramped to $280{ }^{\circ} \mathrm{C}$ at $10{ }^{\circ} \mathrm{C} / \mathrm{min}$ and maintained for 15 minutes giving a total run time of 40 minutes. The split injection mode, with split ratio 10 , was used. The injection temperature was $280{ }^{\circ} \mathrm{C}$ and the injection volume was $1 \mu 1$. Helium was used as carrier gas which was maintained at $0.09 \mathrm{ml} / \mathrm{min}$ in constant flow mode. Mass spectrometer parameters: electron impact ionization mode with electron energy of $70-\mathrm{eV}$, the interface temperature and ion source temperature were kept $280{ }^{\circ} \mathrm{C}$ and $200{ }^{\circ} \mathrm{C}$ respectively. Selected ion monitoring programme (SIM) was used to analyze the gaseous samples to monitor the target analyte.

Five different concentration of commercially available nicotine (TCI) were prepared and their respective peak area was obtained through gas chromatography. A graph was plotted against concentration vs peak area, fitted in a linear plot with regression coefficient value of 0.9956 . After that, the peak area obtained from cigarette (Brand: Goldflake) smoke was obtained and its value on linear plot gave the concentration of nicotine in cigarette smoke. Similarly, the concentration of nicotine in all other cigarette brands were analyzed.

\section{Electrochemical impedance spectroscopy}

Electrochemical impedance spectroscopy (EIS) studies were carried out on CH660E 7 electrochemical workstation. The scan was recorded for a frequency range of $100 \mathrm{kHz}$ to $0.01 \mathrm{~Hz}$ using an alternative voltage of $0.25 \mathrm{~V}$. The impedance data was plotted in Nyquist plot and the data fitted using modified Randles-Sevcik circuit. A $2.5 \mathrm{mM}$ solution of $\mathrm{K}[\mathrm{Fe}(\mathrm{CN}) 6]+2 /+3$ redox pair was used to carry out the EIS measurements. We made $1.4 \mathrm{mg} / \mathrm{ml}$ Ethanolic solution of $\mathbf{1}$ and $\mathbf{1}^{\mathrm{c}}$ (at different concentration of smoke) and $5 \mu \mathrm{M}$ of this ethanolic solution was drop casted on a screen printed electrode for carrying out EIS experiments. To find out the true limit of detection, activated MONT 1 was exposed to cigarette smoke for different intervals of time varying from 5 seconds to 55 seconds. For each time duration, the concentration of nicotine in smoke chamber was measured by GC-MS. Samples of MONT 1 at these nicotine concentration were collected and further EIS studies were carried out to check the concentration-dependence of 
the MONT and also graph of response versus concentration was plotted to find out the limit of detection.

Response of the material was studied through electrochemical impedance spectroscopy (EIS).

Response was calculated by

$\mathrm{R}(\%)=\{(\mathrm{Rf}-\mathrm{Ri}) / \mathrm{Ri}\} \times 100$

Where $\mathrm{Rf}=$ Resistance of the material after smoke exposure $\left(\mathbf{1}^{\mathrm{c}}\right)$ and $\mathrm{Ri}=$ Resistance of the material before smoke exposure (1) 
Table S1: Crystallographic parameters of $\mathbf{1}$.

\begin{tabular}{|c|c|}
\hline Parameter & {$\left[\mathrm{Zn}_{3}(b t c)_{2}(\mu 3-\mathrm{OH})(\mathrm{DMF})\right] \cdot \mathrm{H}_{2} \mathrm{O}(\mathbf{1})$} \\
\hline Formula & C21 H15 N O15 Zn3 \\
\hline $\begin{array}{l}\text { Formula weight, } \\
\text { (g) }\end{array}$ & 717.51 \\
\hline $\mathrm{T}(\mathrm{K})$ & 293(2) \\
\hline Wavelength $(\AA)$ & 0.71073 \\
\hline Crystal system & Tetragonal \\
\hline Space Group & $I 4 \mathrm{c} \mathrm{m}$ \\
\hline a $(\AA)$ & $20.4536(3)$ \\
\hline b $(\AA)$ & $20.4536(3)$ \\
\hline c $(\AA)$ & 17.7854(7) \\
\hline$\alpha\left(^{\circ}\right)$ & 90 \\
\hline$\beta\left({ }^{\circ}\right)$ & 90 \\
\hline$\gamma\left({ }^{\circ}\right)$ & 90 \\
\hline $\mathrm{V}\left(\AA^{3}\right)$ & $7440.5(4)$ \\
\hline $\mathrm{Z}$ & 8 \\
\hline dcalc $\left(\mathrm{gcm}^{-3}\right)$ & 1.281 \\
\hline$\mu \mathrm{MoK} \alpha,\left(\mathrm{cm}^{-1}\right)$ & 1.972 \\
\hline $\mathrm{R} 1(\mathrm{I}>2 \sigma \mathrm{I})$ & 0.0575 \\
\hline WR2(all) & 0.1828 \\
\hline CCDC No. & 1903397 \\
\hline
\end{tabular}


Table S2: Analytes exposed to 1.

\begin{tabular}{|c|c|c|c|}
\hline S. No. & Material & Exposure time & $\begin{array}{l}\text { Color change after } \\
\text { exposure }\end{array}$ \\
\hline 1 & Cigarette smoke & 50 seconds & Dark pink \\
\hline 2 & Nicotine (liquid) & 1 minute & Red \\
\hline 3 & Nicotine vapour & 55 seconds & Dark pink \\
\hline 4 & Carbon Monoxide & 30 minutes & No change \\
\hline 5 & Methane & 30 minutes & No change \\
\hline 6 & Ammonia & 30 minutes & No change \\
\hline 7 & Carbon Dioxide & 30 minutes & No change \\
\hline 8 & Benzene & 30 minutes & No change \\
\hline 9 & Phenol & 30 minutes & No change \\
\hline 10 & Formaldehyde & 30 minutes & No change \\
\hline 11 & Acetaldehyde & 30 minutes & No change \\
\hline 12 & 1,3-butadiene & 30 minutes & No change \\
\hline 13 & Toluene & 30 minutes & No change \\
\hline 14 & Flue gas mixture & 30 minutes & No change \\
\hline 15 & Coconut Coir & 30 minutes & No change \\
\hline 16 & Rice paddy & 30 minutes & No change \\
\hline 17 & Mango Wood & 30 minutes & No change \\
\hline
\end{tabular}


Table S3: Nicotine sensing in different brands of Cigarette available locally.

\begin{tabular}{|c|c|c|c|c|}
\hline S. No. & $\begin{array}{c}\text { Brand name } \\
\text { (available in and } \\
\text { around Mohali, India) }\end{array}$ & $\begin{array}{c}\text { Nicotine concentration } \\
\text { (as obtained by GC-MS) } \\
(\mathbf{i n} \boldsymbol{\mu M})\end{array}$ & $\begin{array}{c}\text { Color } \\
\text { change } \\
\text { (Yes or No) }\end{array}$ & $\begin{array}{c}\text { Response time } \\
\text { (in seconds) }\end{array}$ \\
\hline 1 & Goldflake & 194.2 & Yes & $20-50$ \\
\hline 2 & Wills & 231.6 & Yes & $22-55$ \\
\hline 3 & Pine & 127.7 & Yes & $25-50$ \\
\hline 4 & Goldflake premium & 95.4 & Yes & $20-55$ \\
\hline 5 & Dunhill & 68.2 & Yes & $20-50$ \\
\hline 6 & Marlboro & 62.8 & Yes & $20-50$ \\
\hline 7 & Classic & 64.9 & & \\
\hline
\end{tabular}




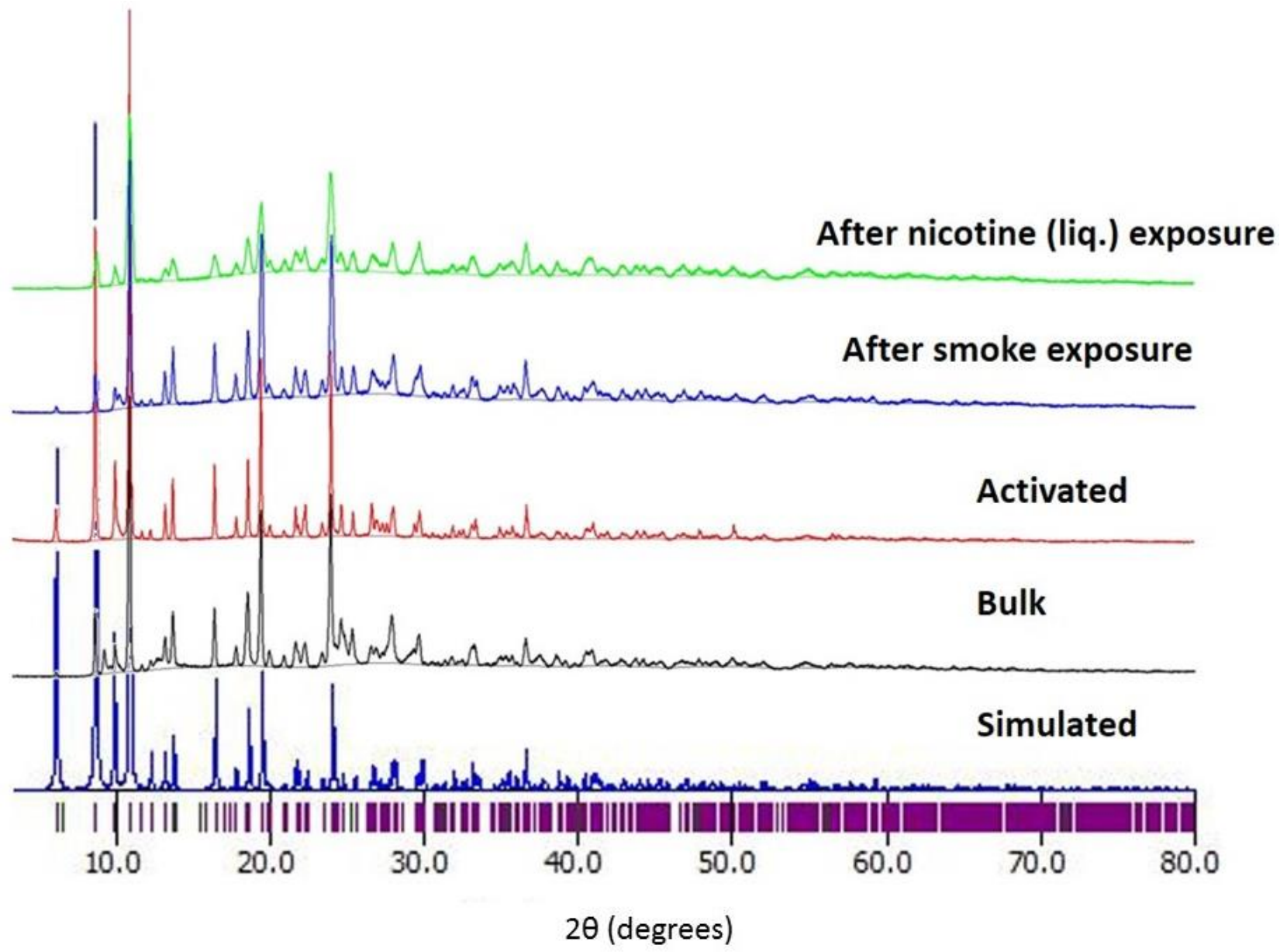

Figure S1: Simulated Powder X-Ray diffraction patterns 1 matched with XRD patterns of bulk (as synthesized), activated, after smoke and liquid nicotine exposure. 
Thermogravimetric Analysis:

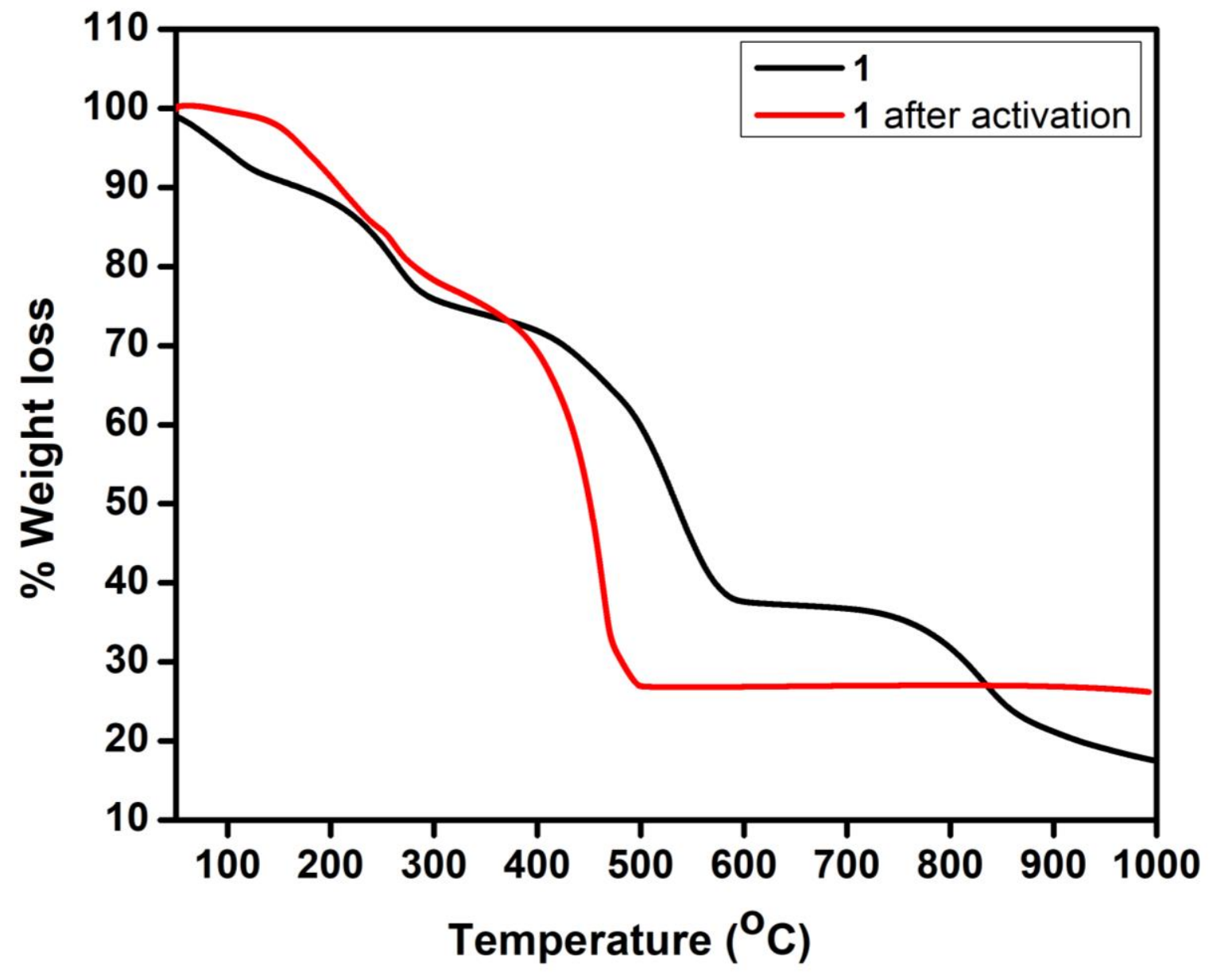

Figure S2: TG analysis of $\mathbf{1}$ as synthesized and after activation. 


\section{Experimental set up for nicotine sensing from cigarette smoke}

Solid crystals of MONT 1 was exposed to various brands of cigarettes available locally in a homemade basic smoke chamber in presence of visible light source (50 $\mathrm{W}$ tungsten bulb). The set up has been shown below in Figure S3. After exposing crystals of $\mathbf{1}$ to smoke for about 20 seconds light yellow crystals of $\mathbf{1}$ starts changing its color to light pink and after continued exposure to 50 seconds it becomes dark pink. The concentration of nicotine created by cigarette smoke in 55 seconds was then analysed through Gas chromatography (Schimadzu GC-MS2014). A schematic representation of this reaction has been shown in Figure S4.The various brands of cigarettes with their concentration has been shown in Table S3.
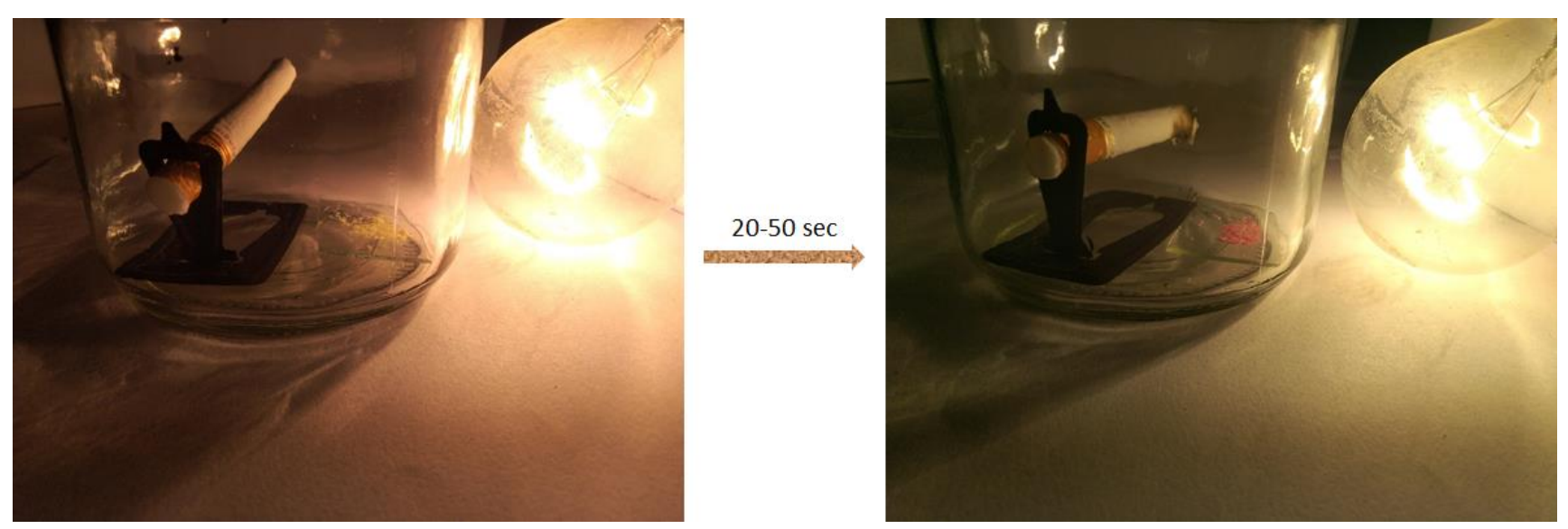

Figure S3. Experimental set up before and after lighting of cigarette. 

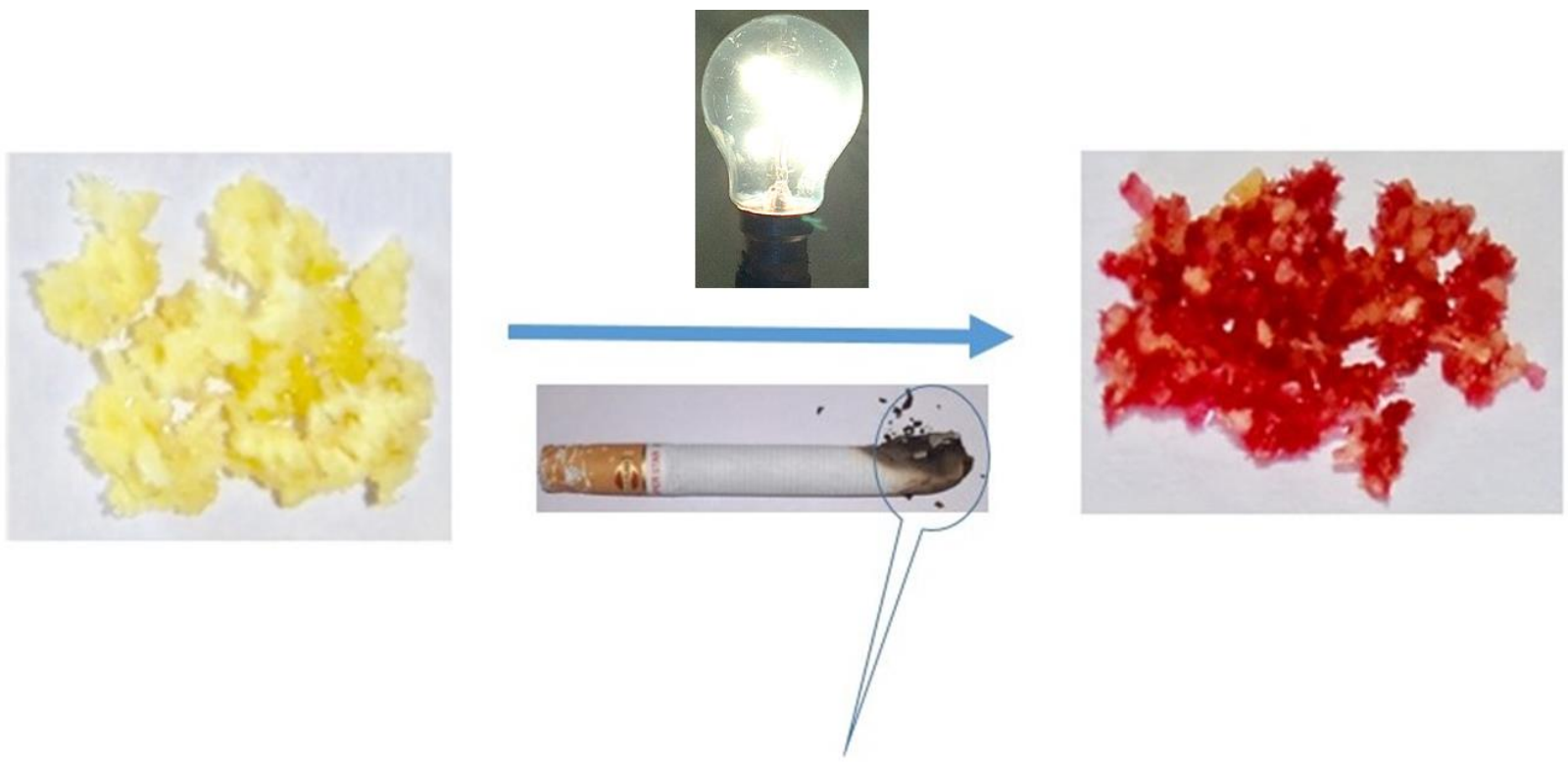

Smoke created by this much area was analyzed through GC-MS

Figure S4. Color change of MONT 1 by exposure to cigarette smoke. 


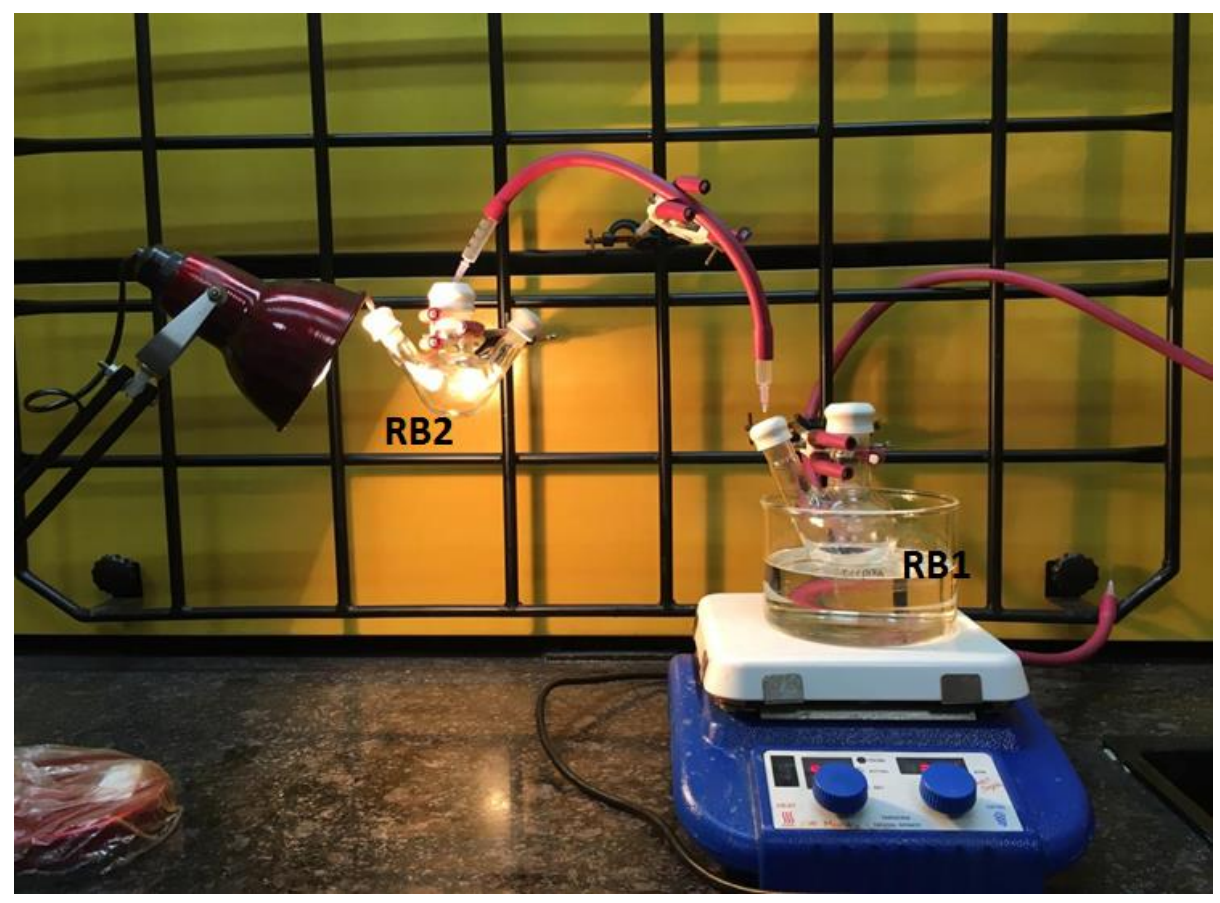

Figure S5: Laboratory set up for nicotine vapour experiment. 
Optical properties with respect to band gap was determined using diffused reflectance spectroscopy taking $\mathrm{BaSO}_{4}$ as reference. The band gap $\left(\mathrm{E}_{\mathrm{g}}\right)$ was calculated by following equation:

$$
\alpha h v=\mathrm{A}\left(h v-\mathrm{E}_{\mathrm{g}}\right)^{1 / 2}
$$

where, $\alpha$ is absorption coefficient, $h v$ is discrete photon energy and $\mathrm{A}$ is a constant relative to the material. The absorption coefficient $(\alpha)$ can be related to Kubelka-Munk function as follows:

$\mathrm{F}(\mathrm{R})=(1-\mathrm{R})^{2} / 2 \mathrm{R}=\alpha / \mathrm{S}$

$\mathrm{R}=\mathrm{R}$ sample $/ \mathrm{R}_{\mathrm{BaSO}} 4$

where, $F(R)$ is the Kubelka-Munk function, $R$ is reflectance and $S$ is scattering coefficient. So, the band gap of $\mathbf{1}$ and $\mathbf{1}^{\mathbf{c}}$ can be obtained from the plot of (F(R) $\left.h v\right)^{2}$ vs $h v$ (Tauc Plot), by extrapolating the linear regime of the resulting curves to $F(R)=0$.

Herein a energy band gap of $3.54 \mathrm{eV}$ for $\mathbf{1}$ and three band gaps at $1.72 \mathrm{eV}, 2.58 \mathrm{eV}$ and $3.45 \mathrm{eV}$ for $\mathbf{1}^{\mathbf{c}}$ was obtained (Figure $\mathbf{S 6}$ ).

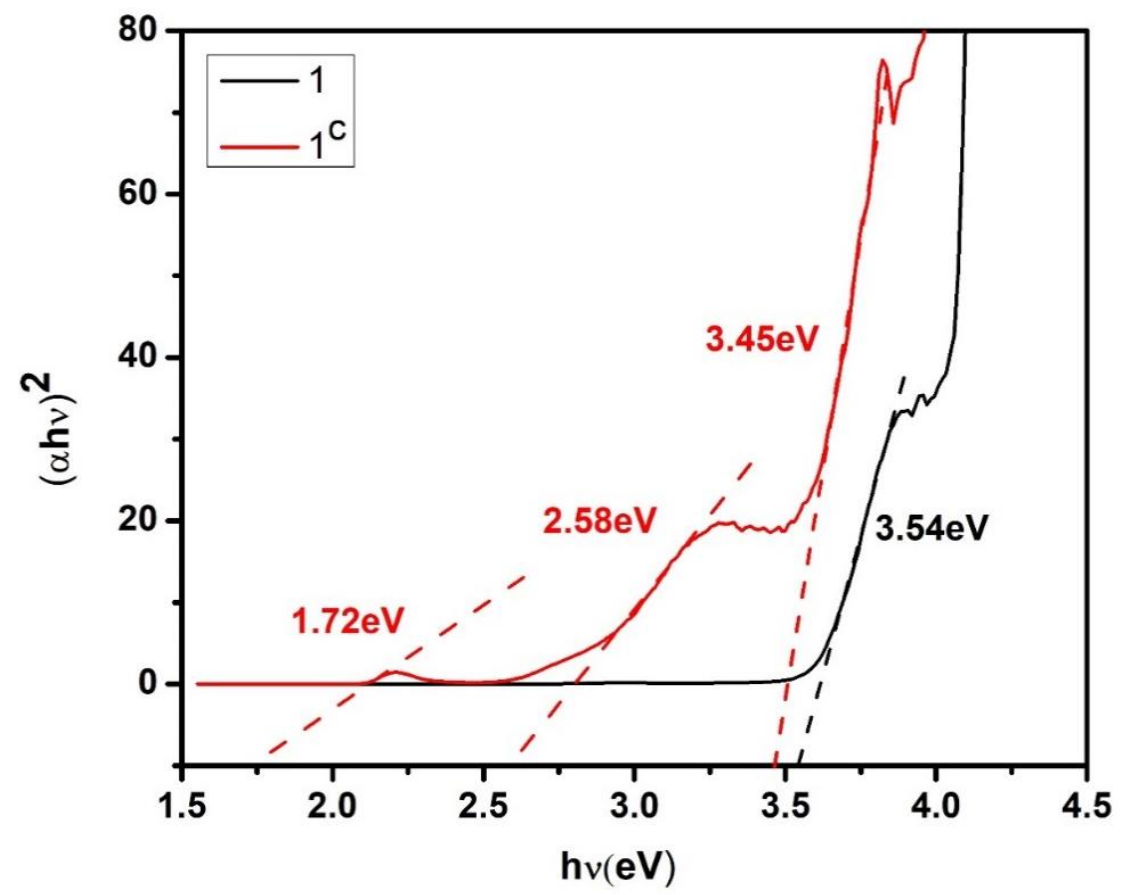

Figure S6: Tauc Plot: Band gap of $\left[\mathrm{Zn}_{3}(b t c)_{2}(\mu 3-\mathrm{OH})(\mathrm{DMF})\right] . \mathrm{H}_{2} \mathrm{O}, \mathbf{1}$ before and after cigarette smoke exposure. 

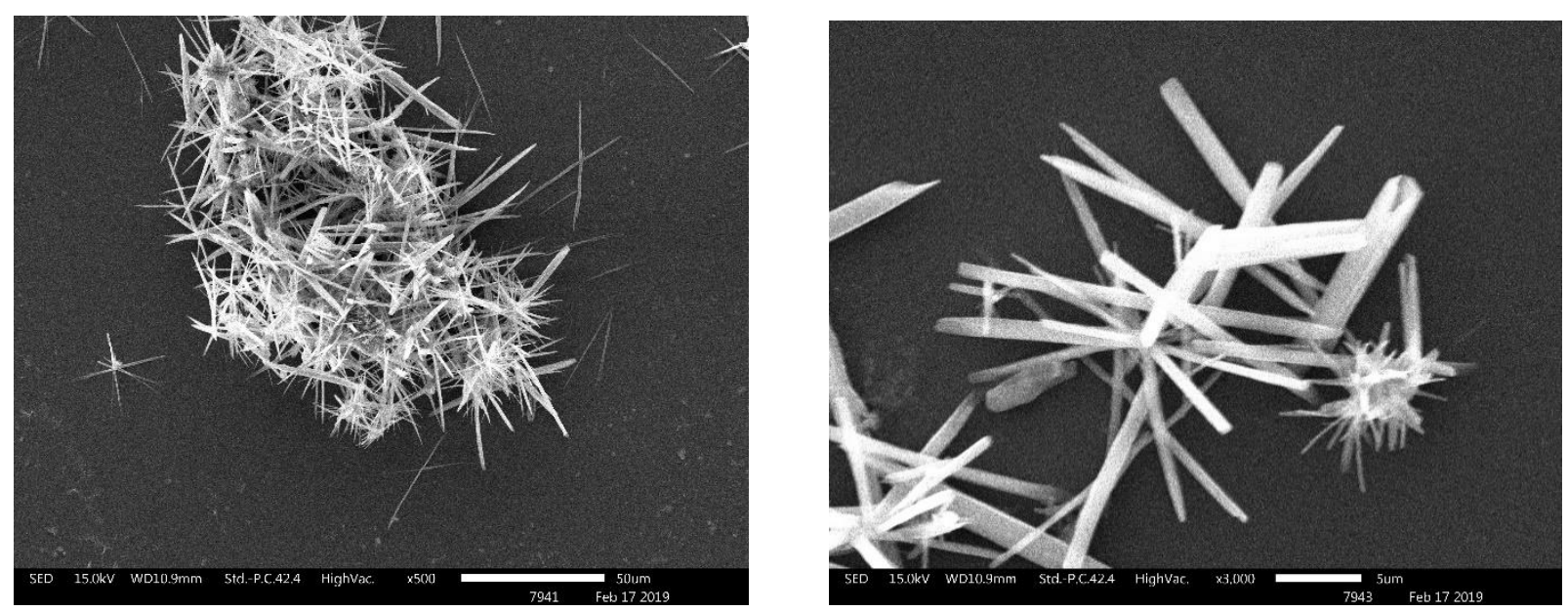

Figure S7: SEM images of $\left[\mathrm{Zn}_{3}(b t c)_{2}(\mu 3-\mathrm{OH})(\mathrm{DMF})\right] . \mathrm{H}_{2} \mathrm{O}, \mathbf{1}$

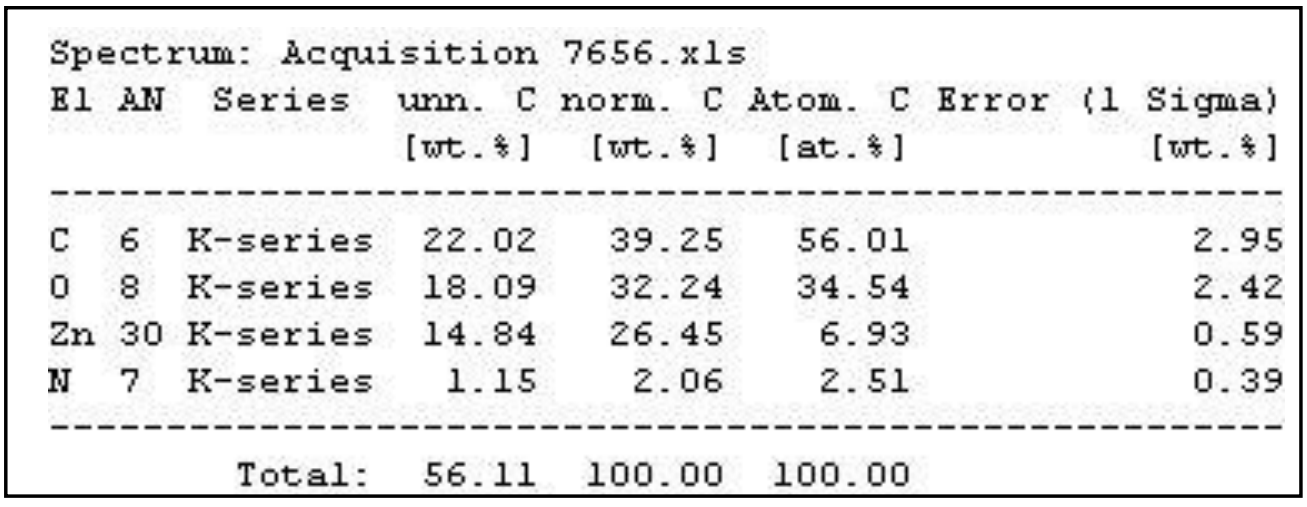

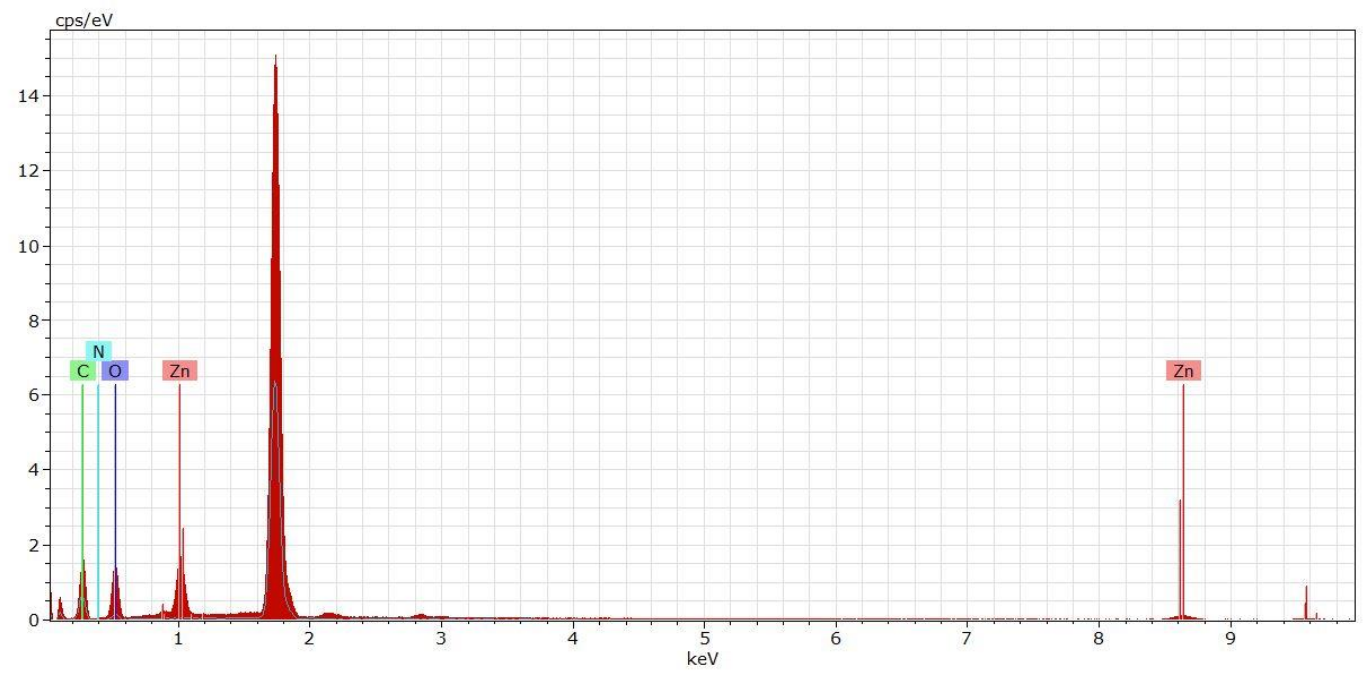

Figure S8: EDX spectra of $\left[\mathrm{Zn}_{3}(b t c)_{2}(\mu 3-\mathrm{OH})(\mathrm{DMF})\right] . \mathrm{H}_{2} \mathrm{O}, \mathbf{1}$ 

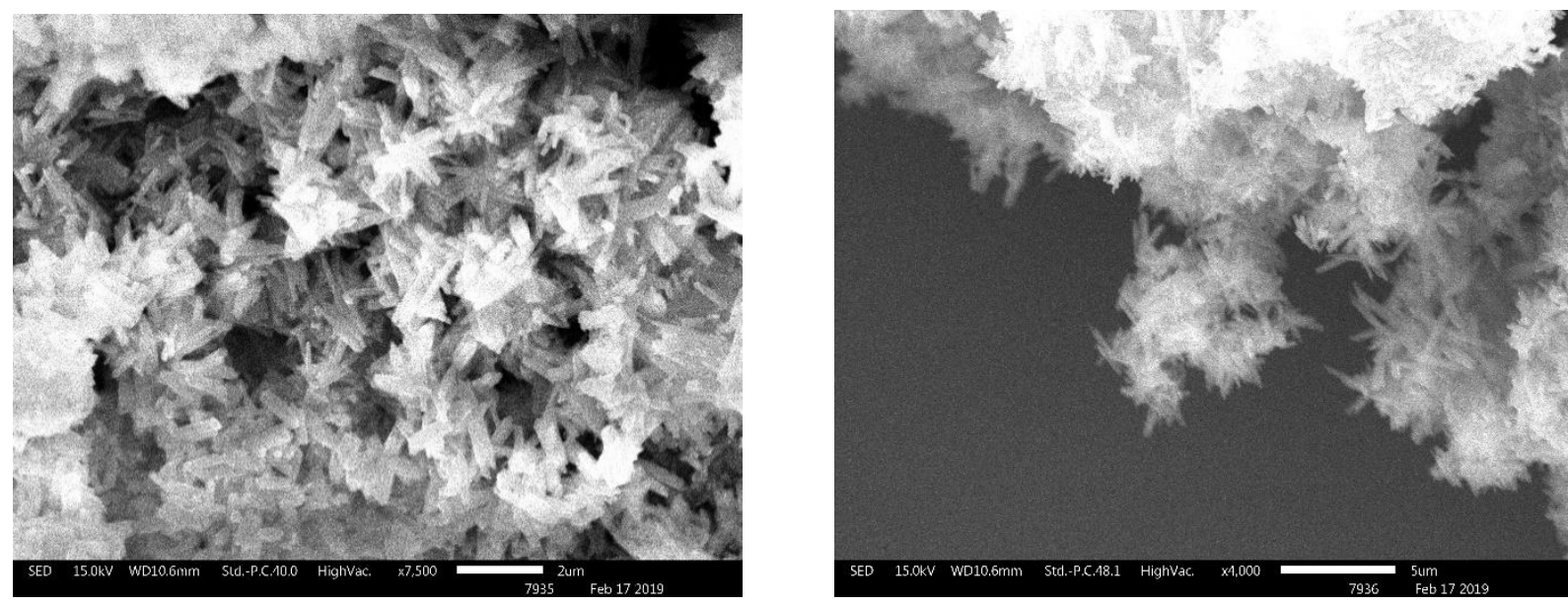

Figure S9: SEM images of $\mathbf{1}$ after cigarette smoke exposure $\left(\mathbf{1}^{\mathrm{c}}\right)$.

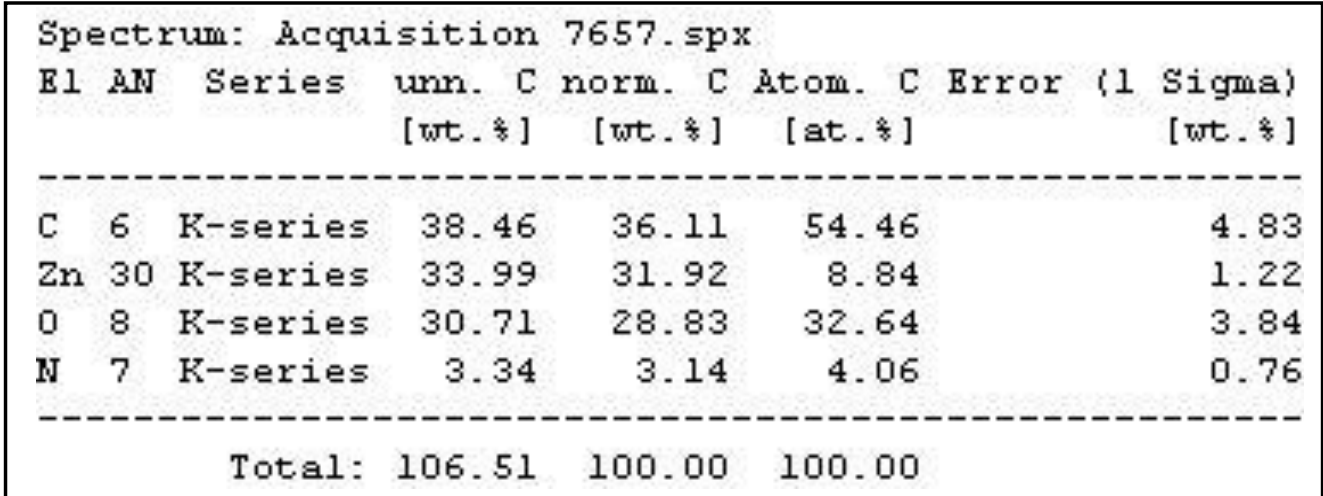

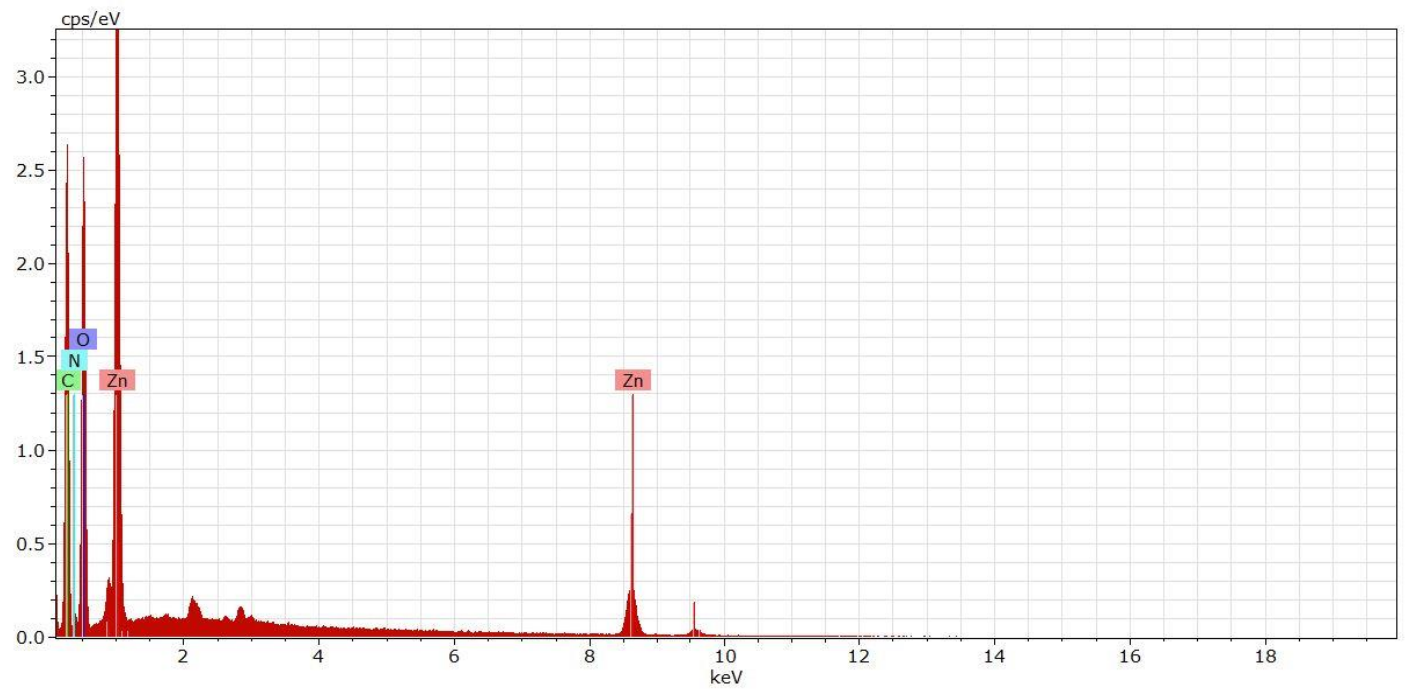

Figure S10: EDX of 1 after cigarette smoke exposure $\left(\mathbf{1}^{\mathrm{c}}\right)$. 

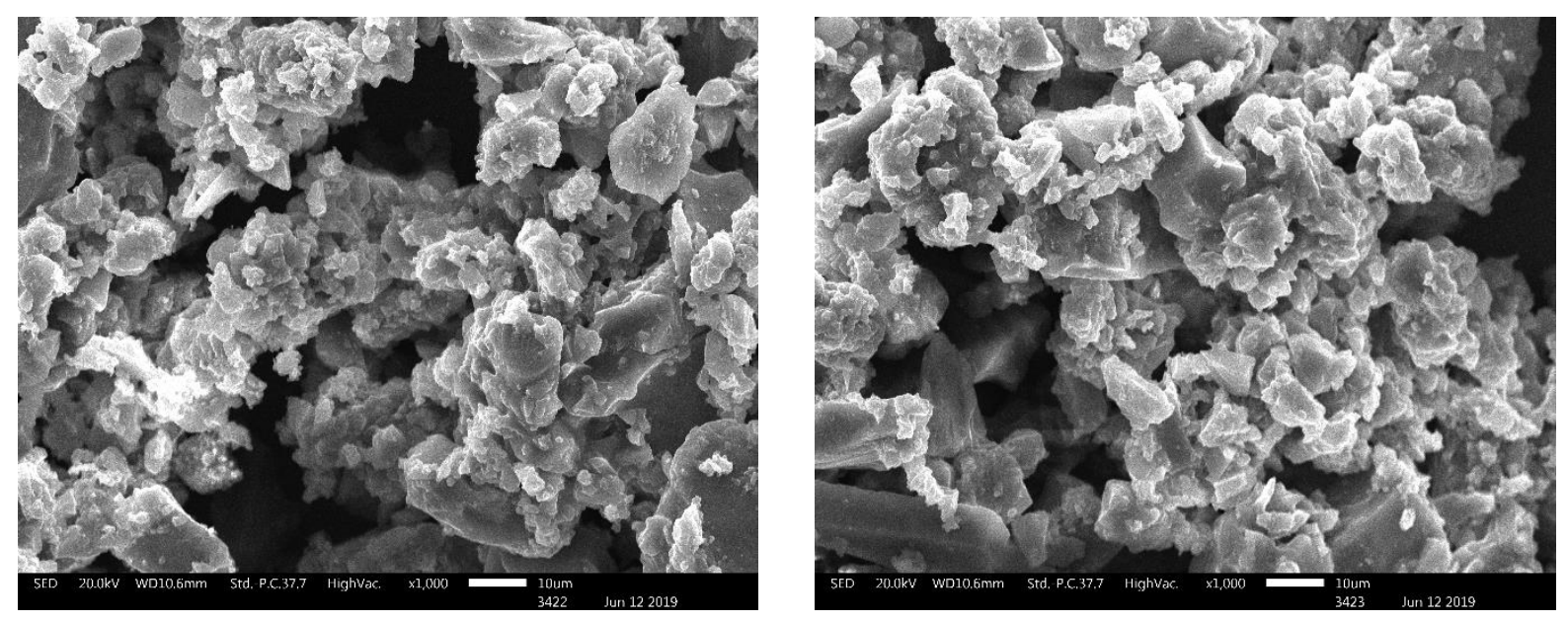

Figure S11: SEM images of $\mathbf{1}$ after liquid nicotine exposure $\left(\mathbf{1}^{\mathbf{n}}\right)$.

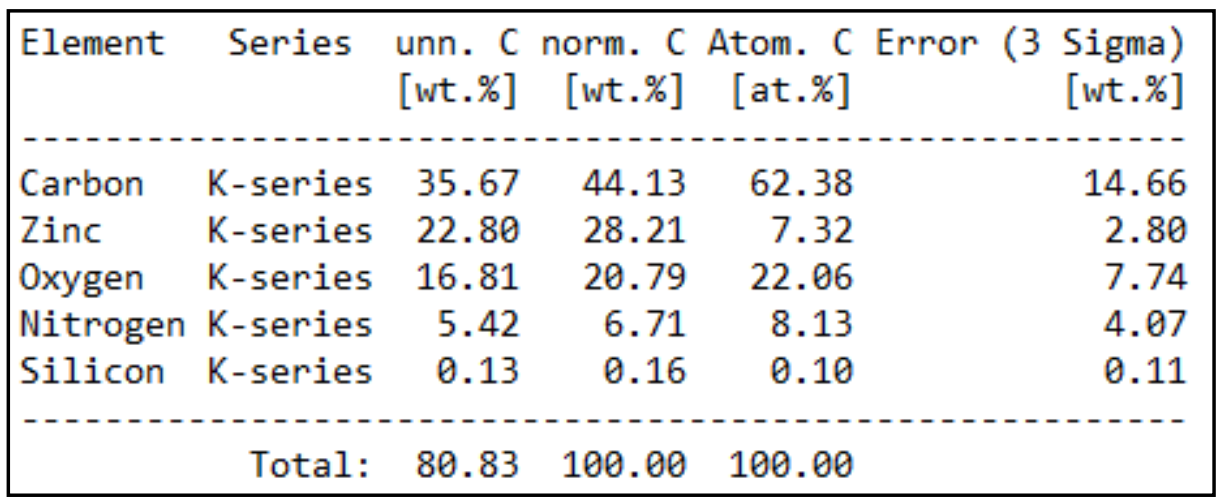

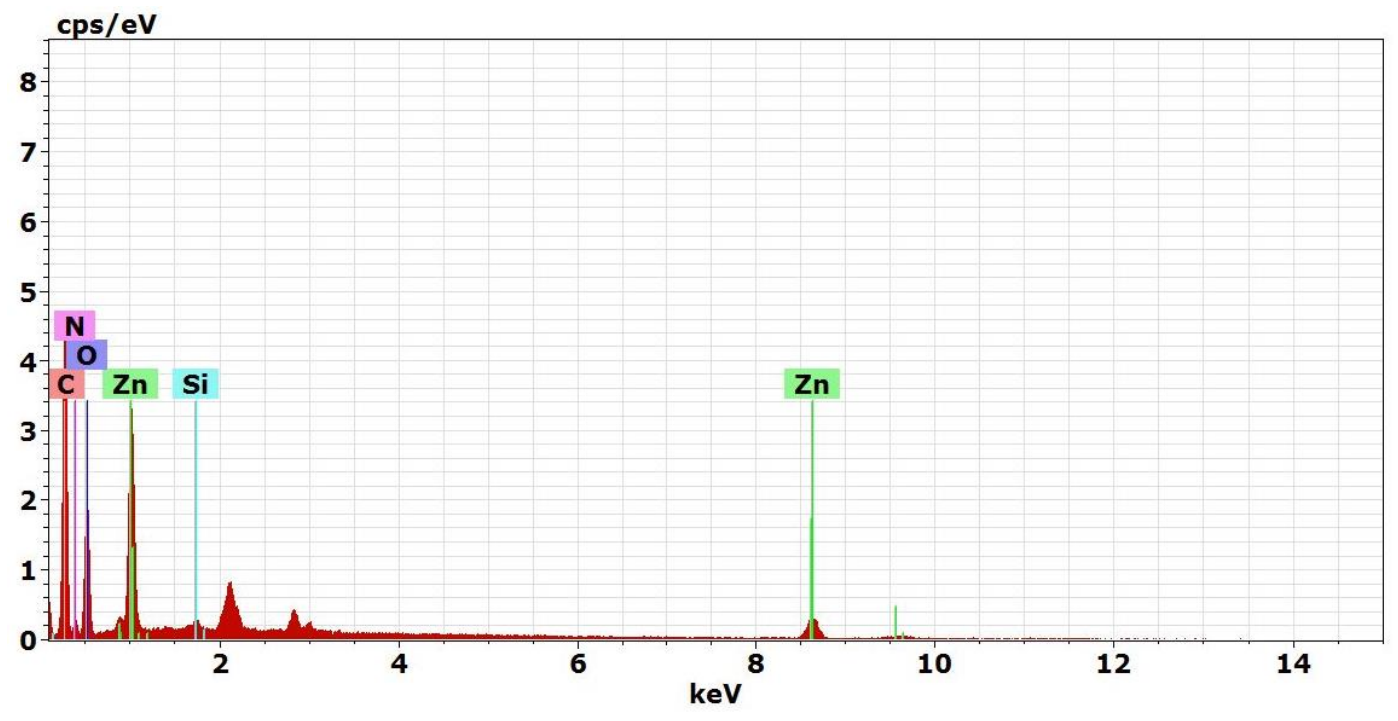

Figure S12: EDX of 1 after liquid nicotine exposure $\left(\mathbf{1}^{\mathbf{n}}\right)$. 


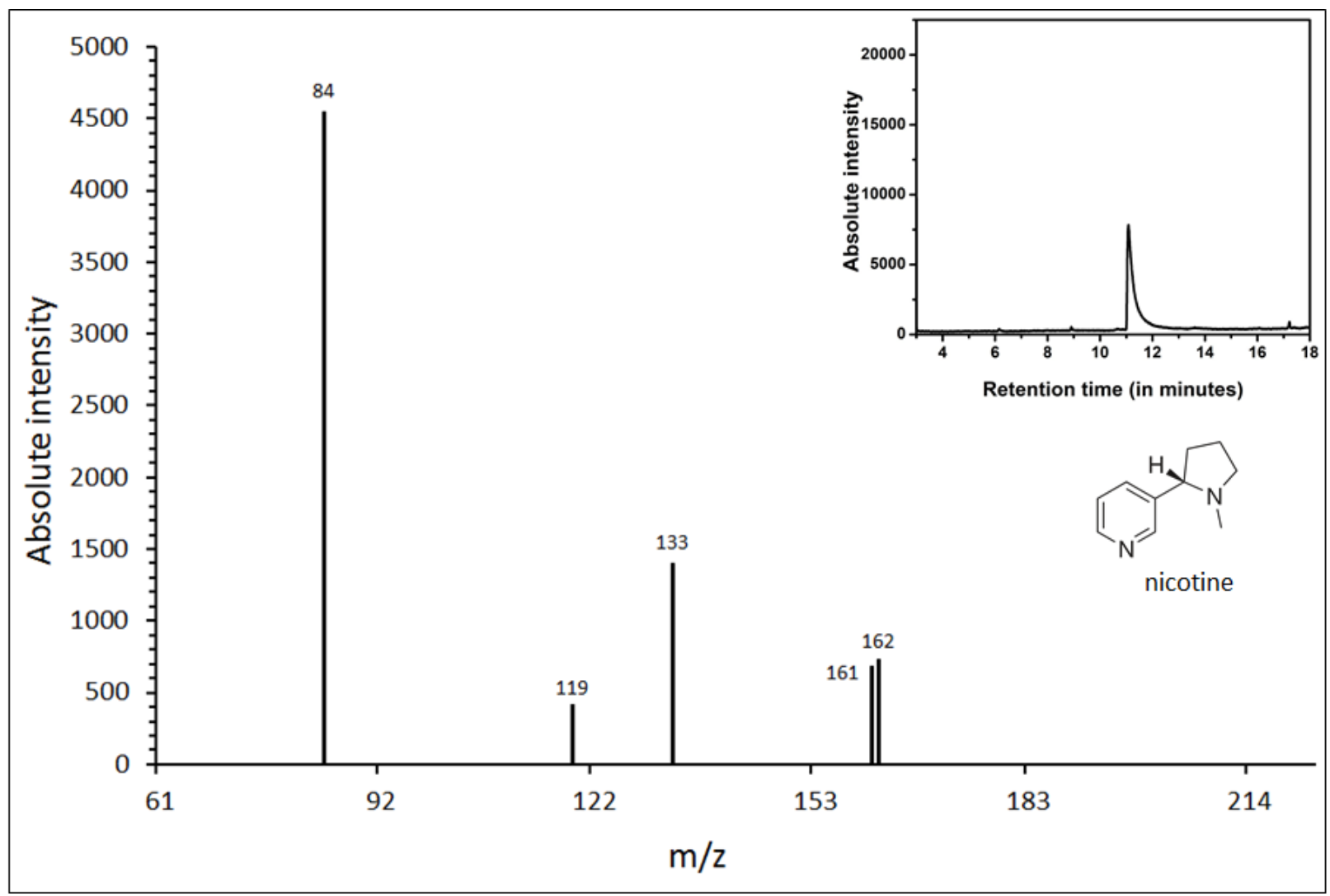

Figure S13. Mass spectra of nicotine from cigarette smoke. Inset showing GC chromatogram. 


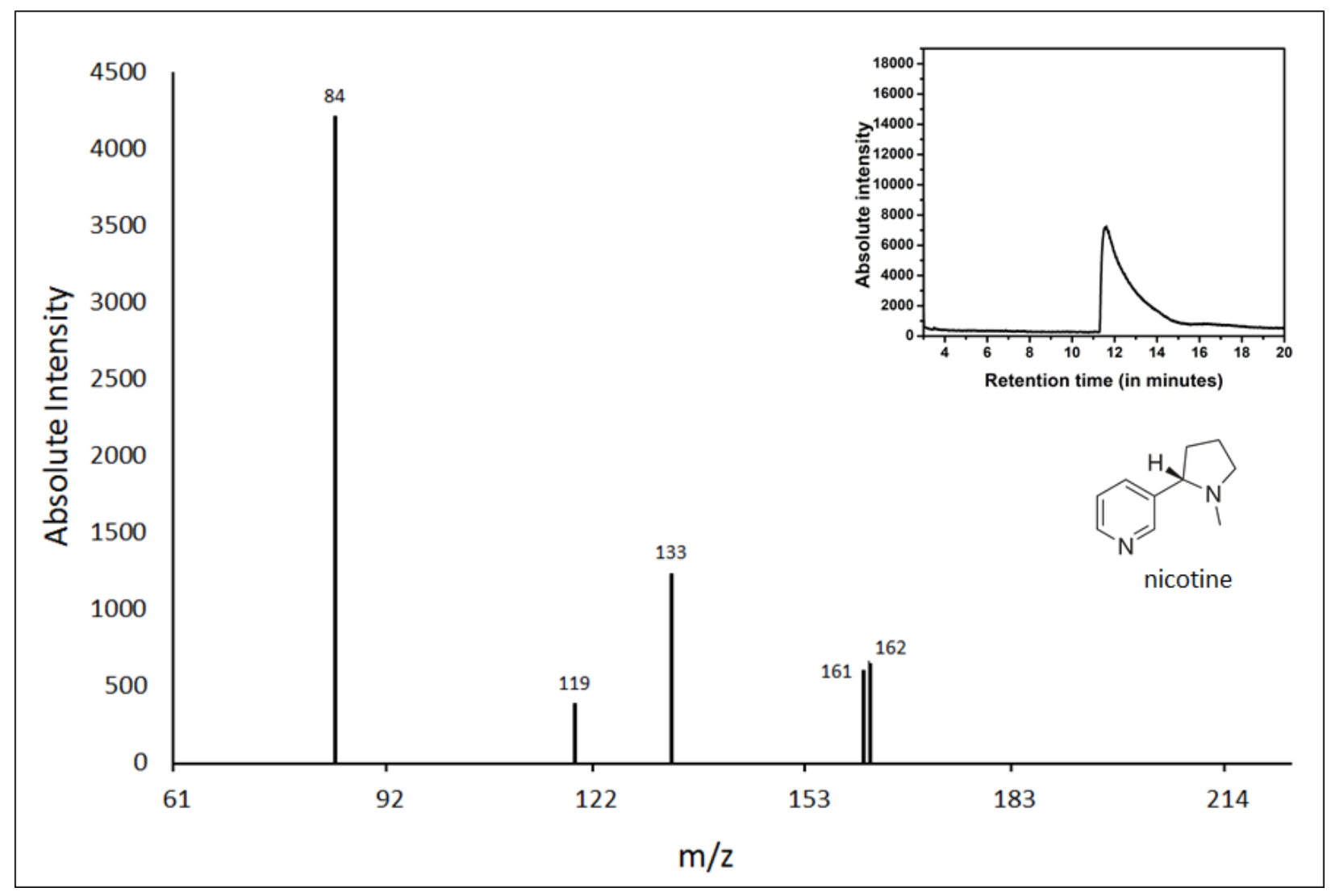

Figure S14. Mass spectra of liquid nicotine. Inset showing GC chromatogram. 


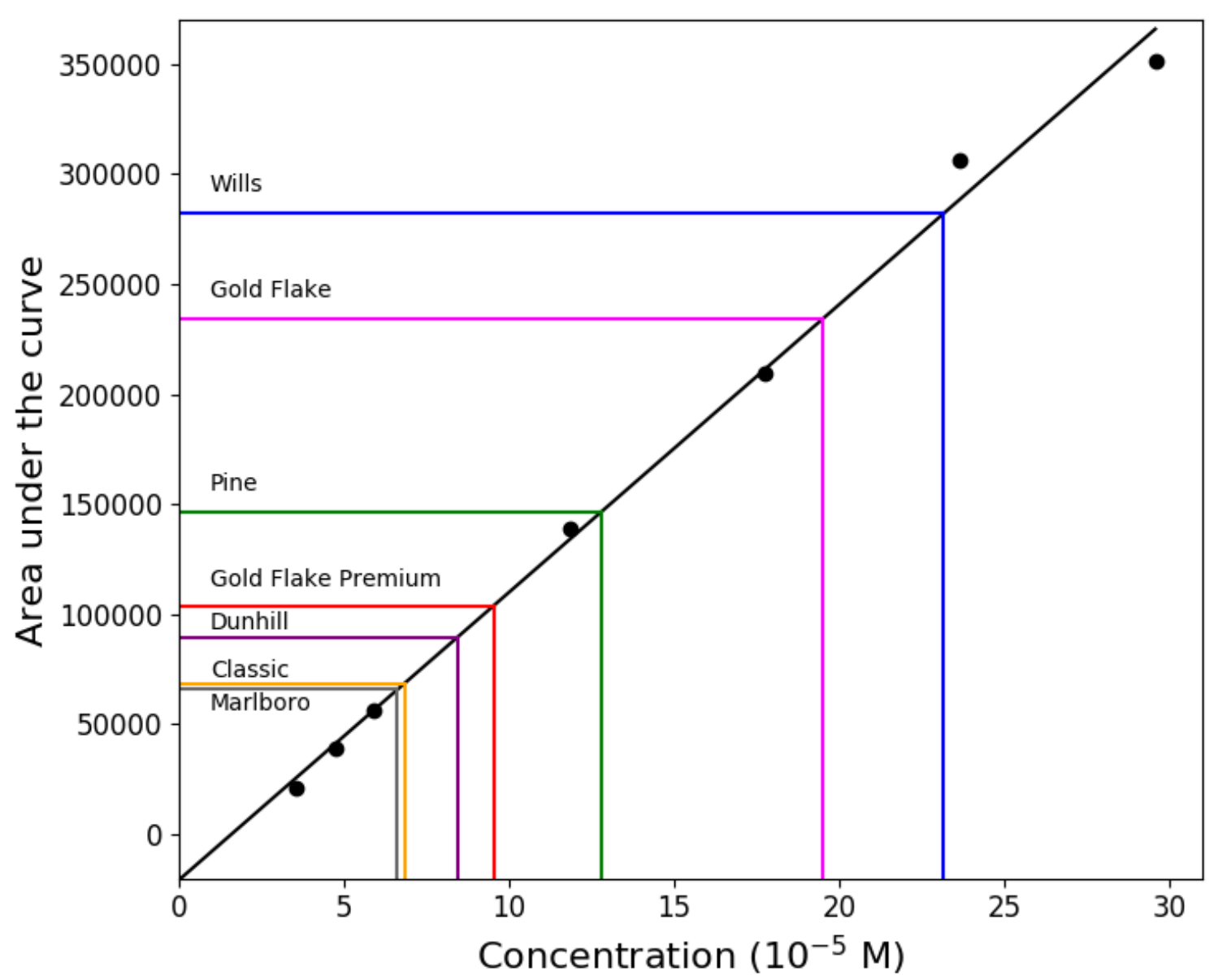

Figure S15: Linear fit for the estimation of concentration of nicotine in various brands of cigarette smoke after exposure to MONT 1 for maximum $55 \mathrm{sec}$. 


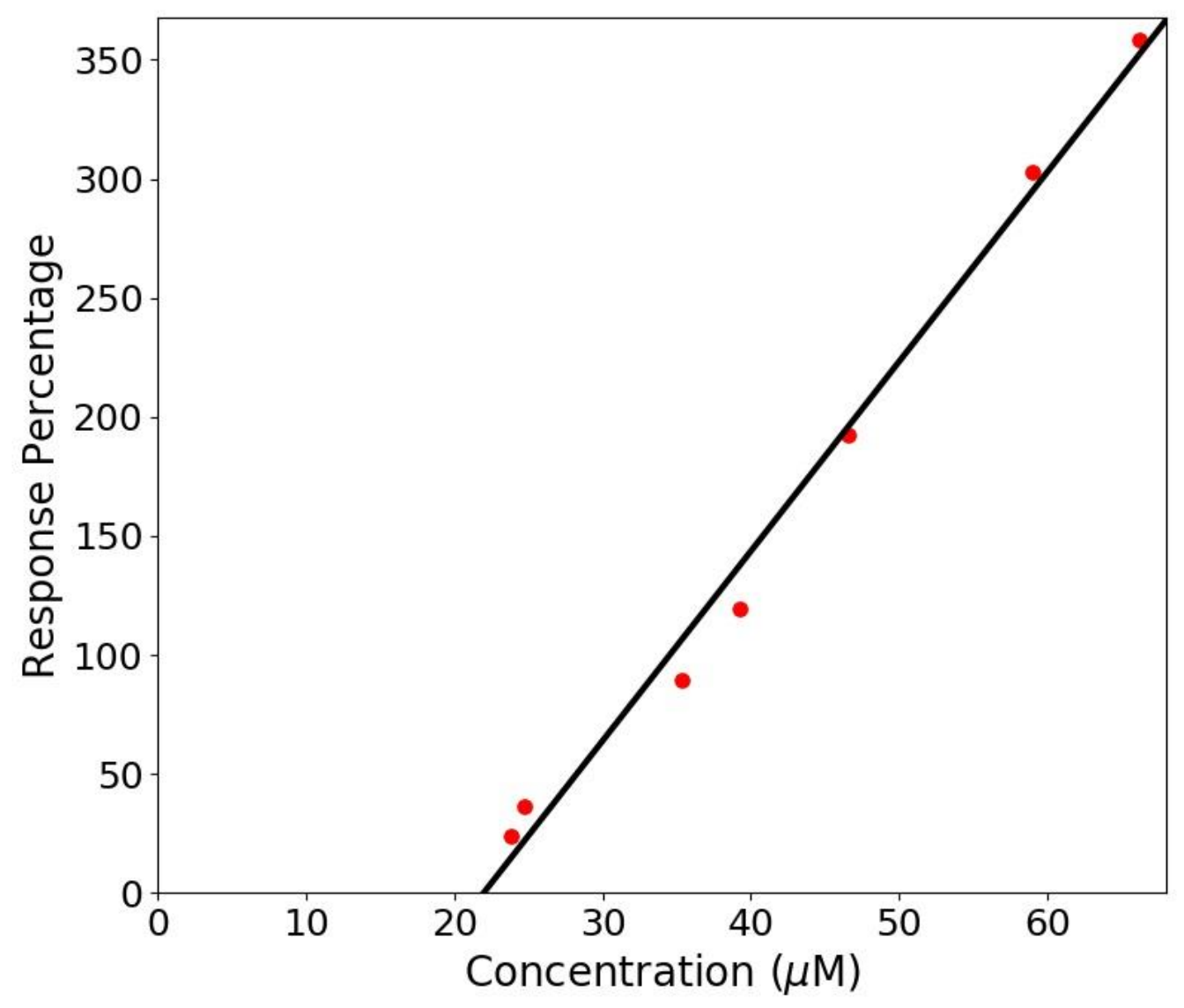

Figure S16: Response/ sensitivity versus concentration of nicotine in cigarette smoke. 


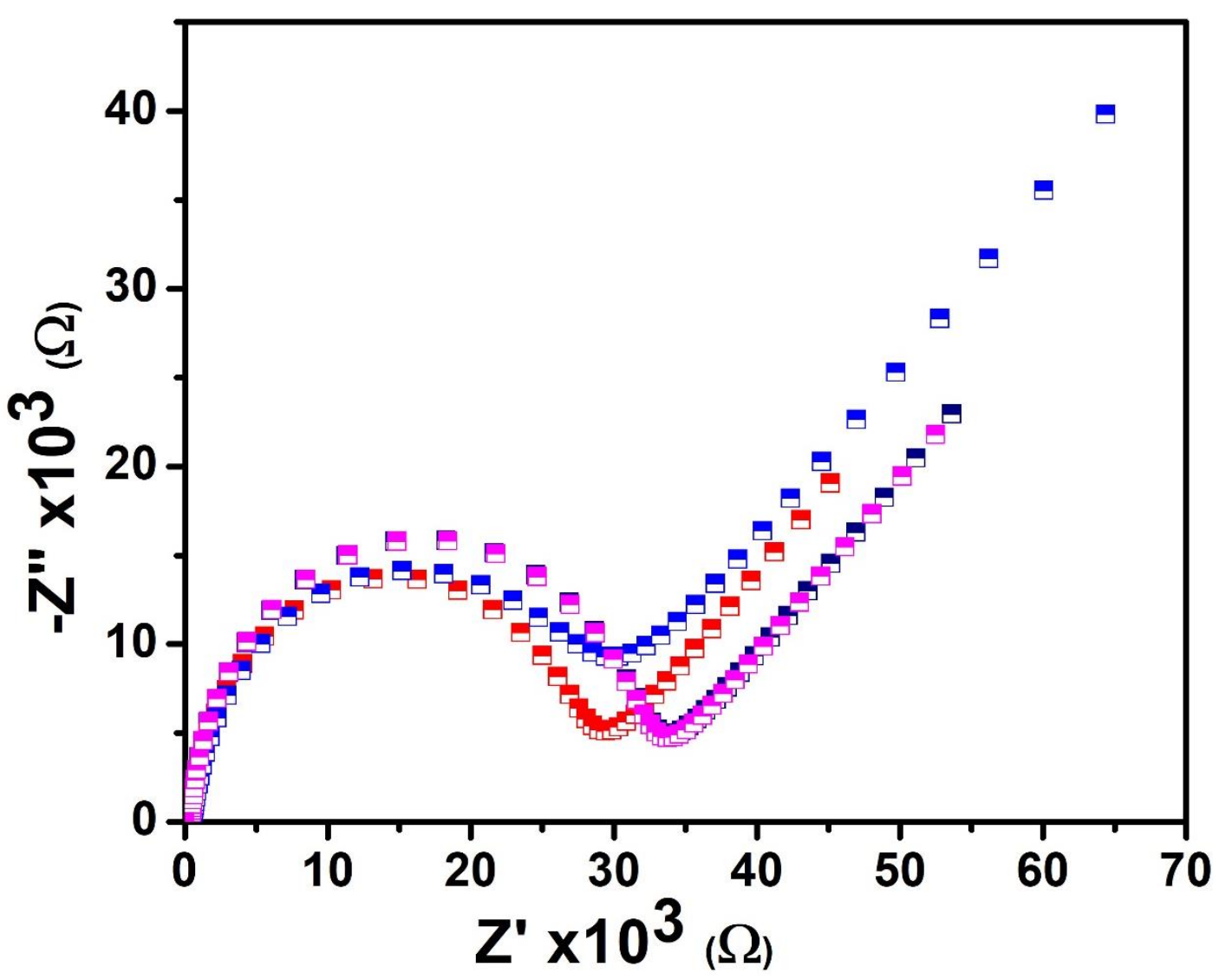

Figure S17: Nyquist diagrams of 1 showing reproducibility of EIS studies at a concentration of $1.4 \mathrm{mg} / \mathrm{ml}$.

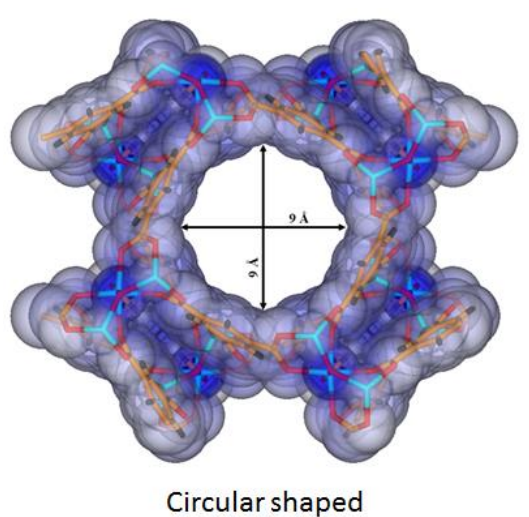

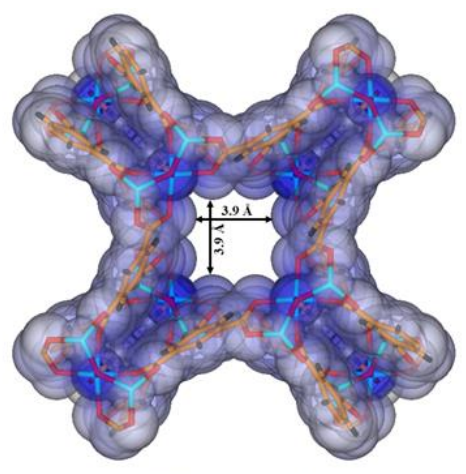

Star shaped

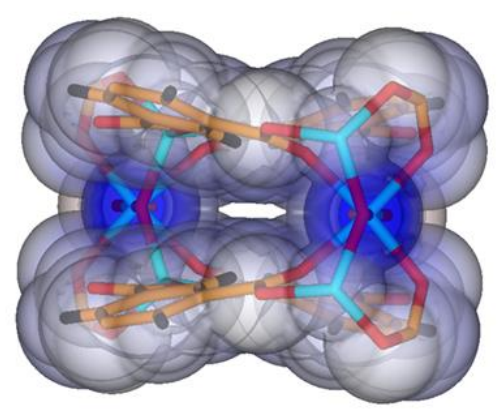

Oval shaped

Figure S18: Three different shaped channels in MONT 1. 


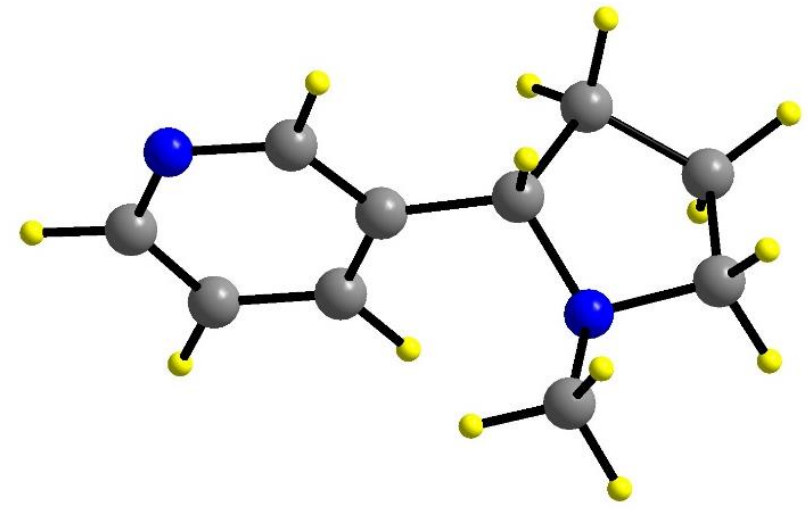

Figure S19: Optimised structure of nicotine. 


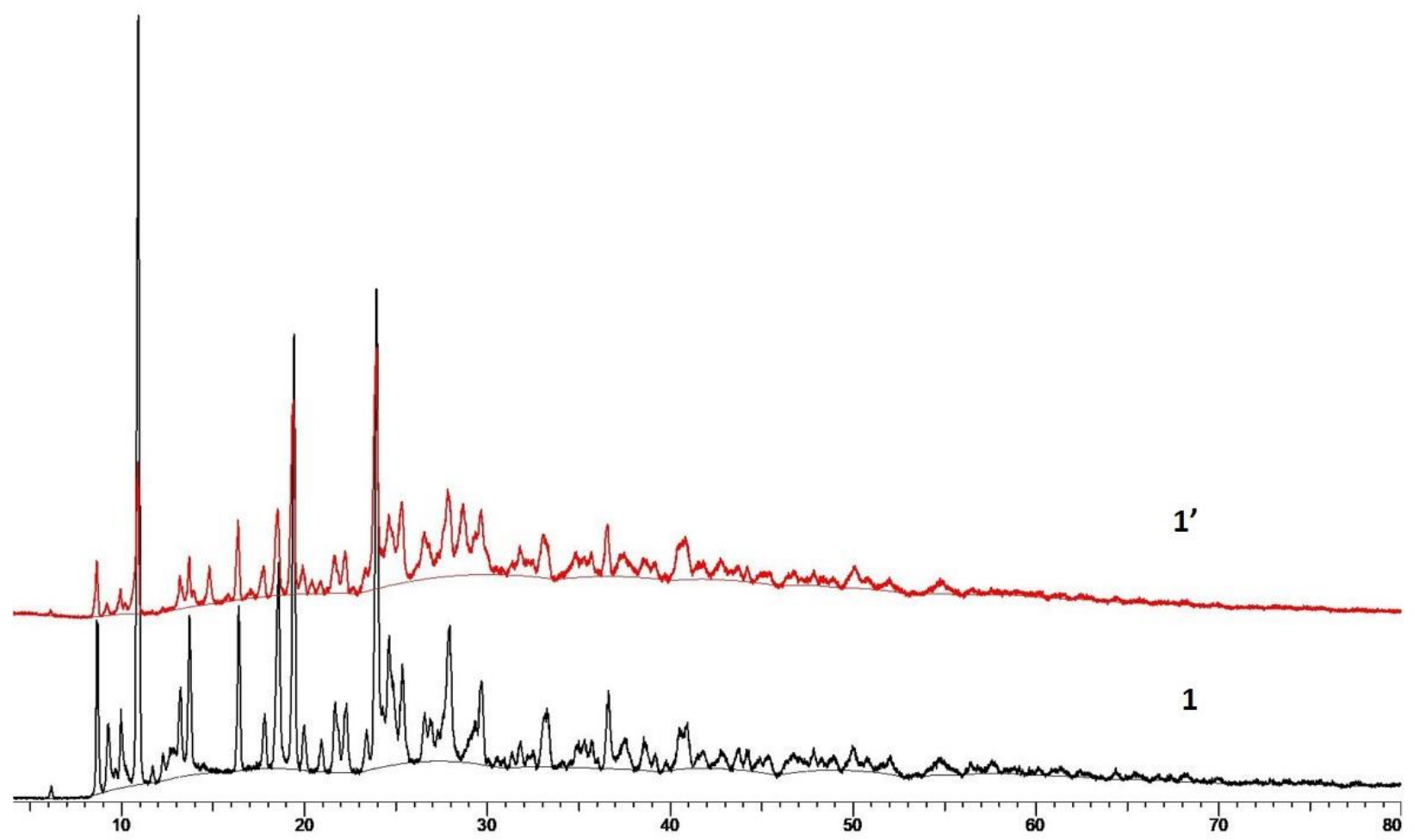

Figure S20: PXRD spectra of as synthesized $\left[\mathrm{Zn}_{3}(\text { btc })_{2}(\mu 3-\mathrm{OH})(\mathrm{DMF})\right] \cdot \mathrm{H}_{2} \mathrm{O}$, (1) and the recycled material $\left(\mathbf{1}^{\prime}\right)$ i.e. $\mathbf{1}^{\mathbf{c}}$ comes back to the original structure after keeping it in ambient conditions. 


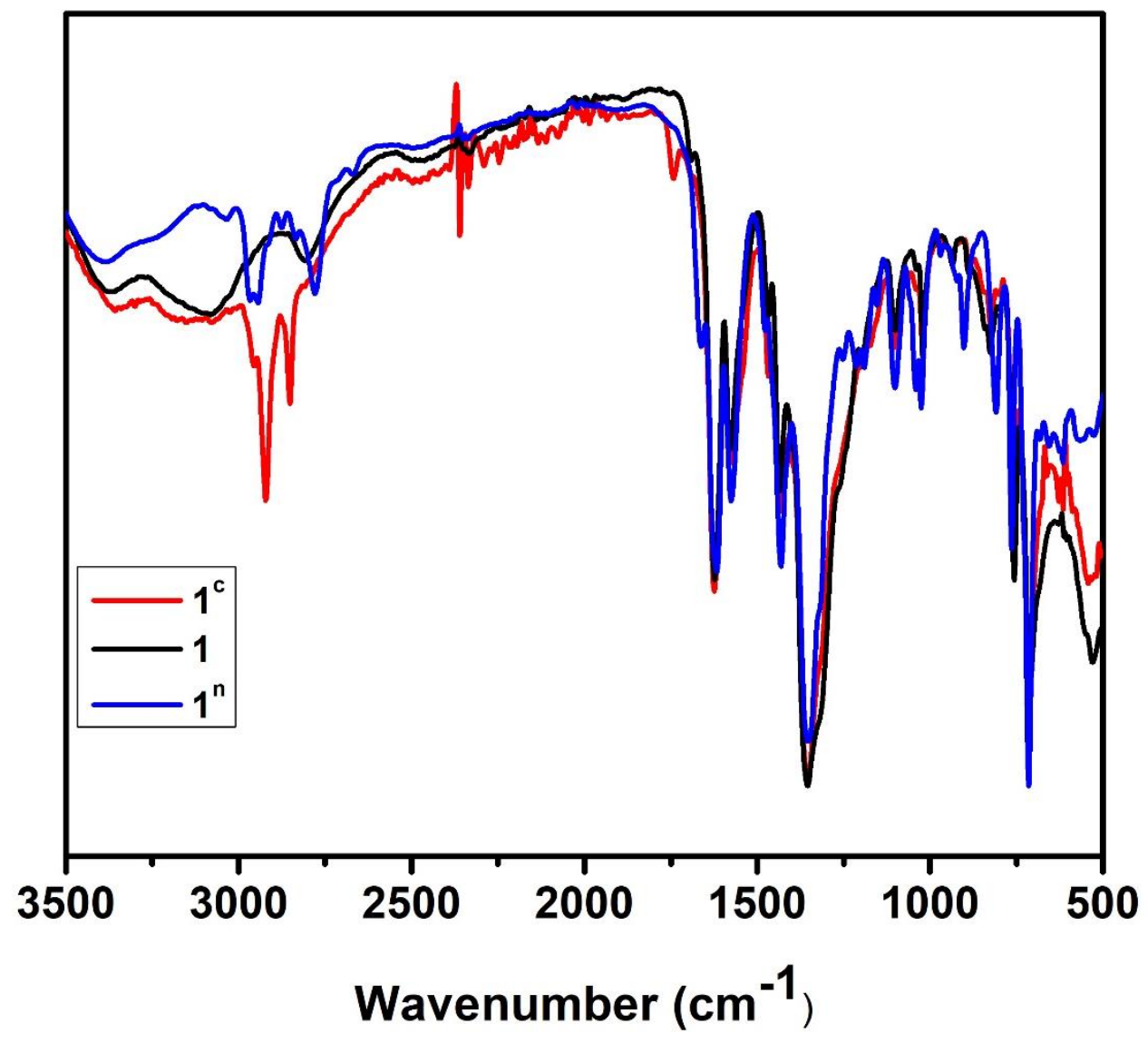

Figure S21: FTIR spectroscopy shows the presence of nicotine in $\mathbf{1}^{\mathbf{c}}$ and $\mathbf{1}^{\mathbf{n}}$ with the presence of bands at $2980 \mathrm{~cm}^{-1}$ and $2800 \mathrm{~cm}^{-1}$ approximately which are characteristic for C-H stretching. The peak around $1677 \mathrm{~cm}^{-1}$ corresponds to aromatic $\mathrm{C}=\mathrm{N}$ double bond stretching and $1690 \mathrm{~cm}^{-1}$ corresponds to $\mathrm{C}=\mathrm{C}$ double bond. $904 \mathrm{~cm}^{-1}$ corresponds to $\mathrm{C}-\mathrm{H}$ bending. But we could not conclude metal-nitrogen (nicotine) bonding through FTIR spectrum. This may be due to very less concentration of nicotine and weak interaction with $\mathrm{Zn}$.

\section{References}

[1] Dolomanov, O.V.; Bourhis, L. J.; Gildea, R. J.; Howard, J. A. K.; Puschmann, H. J. Appl. Cryst. 2009, 42, 339-341.

[2] Burla, M. C.; Caliandro, R.; Caliandro, M.; Carrozzini, B.; Cascarano, G. L.; De Caro, L.;

Giacovazzo, C.; Polidori, G.; Polidori, D.; Spagna, R. J. Appl. Cryst. 2007, 40, 609-613.

[3] Sheldrick, G.M.; ActaCryst. 2015, C71, 3-8. 